\title{
HUMAN RESPONSE TO FIRE:
}

THREE DESIGNS FOR RESEARCH

Fred I. StahI

Environmental Design Research Division

Center for Building Technology

National Engineering Laboratory

National Bureau of Standards

Washington, D.C. 20234

March 20, 1978

U.S. DEPARTMENT OF COMMERCE, Juanita M. Kreps, Secretary

Dr. Sidney Harman, Under Secretary

Jordan J. Baruch, Assistant Secretary for Science and Technology

NATIONAL BUREAU OF STANDARDS, Ernest Ambler, Director 

LIST OF FIGURES ................................ ii

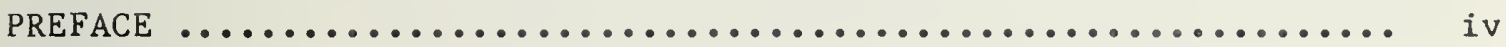

ABSTRACT $\ldots \ldots \ldots \ldots \ldots \ldots \ldots \ldots \ldots \ldots \ldots \ldots \ldots \ldots \ldots \ldots \ldots \ldots \ldots \ldots \ldots \ldots \ldots$

1. INTRODUCTION .................................... 1

1.1 OVERVIEW $\ldots \ldots \ldots \ldots \ldots \ldots \ldots \ldots \ldots \ldots \ldots \ldots \ldots \ldots \ldots \ldots \ldots \ldots \ldots \ldots \ldots \ldots$

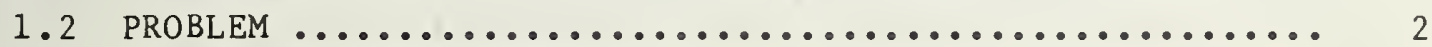

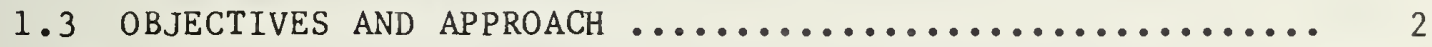

2. DESIGN ONE: AN EXPLORATORY PROCEDURE FOR STUDYING THE

TRANSFORMATION OF "EVERYDAY" ENVIRONMENTAL SETTINGS INTO

"EMERGENCY" SITUATIONS ...........................

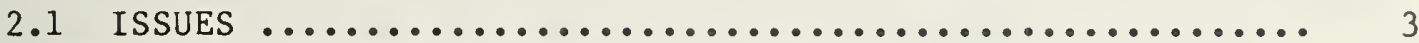

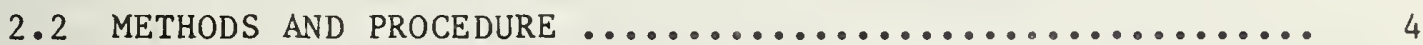

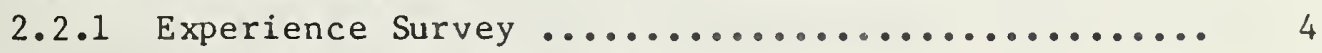

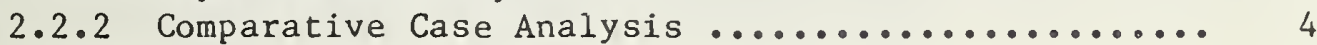

2.2 .3 Summary of Procedure ....................... 7

2.3 UTILITY OF THE DESIGN $\ldots \ldots \ldots \ldots \ldots \ldots \ldots \ldots \ldots \ldots \ldots \ldots \ldots \ldots$

3. DESIGN TWO: A FIELD-EXPERIMENT ON DIFFERENTIAL EMERGENCY

COGNITION

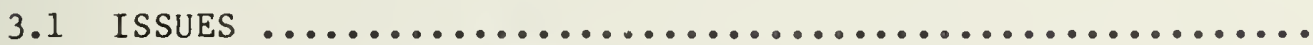

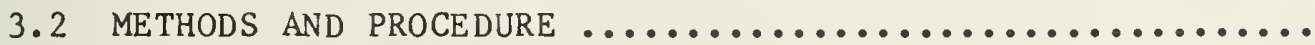

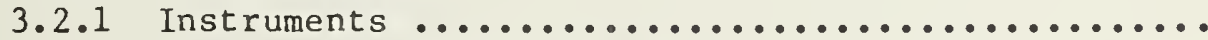

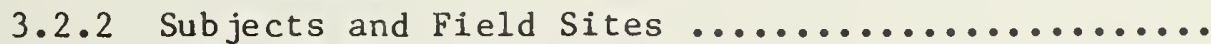

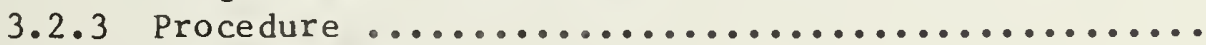

3.3 UTILITY OF THE DESIGN $\ldots \ldots \ldots \ldots \ldots \ldots \ldots \ldots \ldots \ldots \ldots \ldots \ldots \ldots$

4. DESIGN THREE: A FIELD EXPERIMENTAL DESIGN FOR EVALUATING

EMERGENCY TRAINING PROGRAMS ......................

4.1 ISSUES ...................................

4.1.1 Concepts and Operational Definitions............

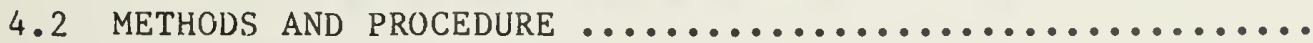

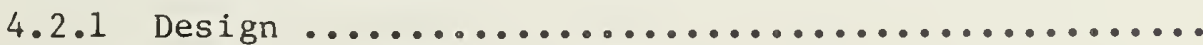

4.2.2 Selecting Research Sites ...................

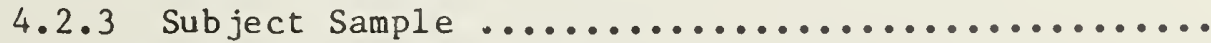

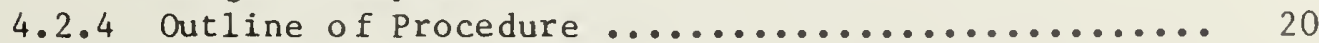

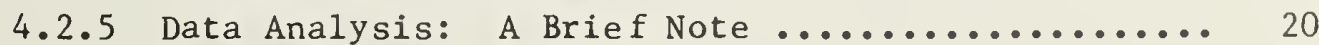

4.3 UTILITY OF THE DESIGN .......................... 21

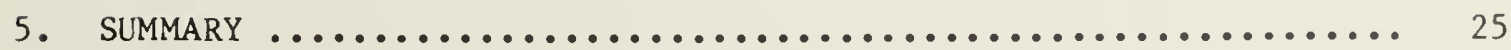


Page

Figure 2.1 APPLICATION OF THE MULTIPLE TIME SERIES

RESEARCH DESIGN .......................... 9

Figure 3.1 FACTORIAL STRUCTURE OF Q-SORT STATEMENT CATEGORIES .. 14

Figure 3.2 SAMPLE Q-SORT STATEMENTS..................... 15

Figure 3.3 FACTORIAL DESIGN FOR HYPOTHESIS (1) ............ 16

Figure 3.4 FACTORIAL DESIGN FOR HYPOTHESIS (2) ............ 17

Figure 4.1 (a) $2 \times 3$ FACTORIAL DESIGN ................... 22

(b) EXPANSION OF THE POST-TEST ONLY CONTROL-GROUP

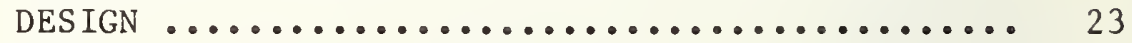

(c) DESIGN EXPANDED FURTHER TO INCLUDE

"RETROSPECTIVE-PRETEST" COVARIATE MEASURES ..... 24 


\section{PREFACE}

The Environmental Design Research Division, Center for Building Technology, NBS, is developing a more complete understanding of building access and egress under both emergency and "everyday" conditions. The responses of building occupants during fire emergencies is an important part of this overall effort.

Many of the ideas presented in this report were formulated by the author at the Environmental Psychology Program, The City University of New York, during 1975 and 1976. These concepts were refined under the CBT Building Access/Egress Research Planning Project, of which the author is the project leader.

Several individuals provided assistance and guidance during the development of research designs presented here, and during the preparation of this report. Dr. Gary Winkel and Dr. Susan Saegert of the Environmental Psychology Program, City University of New York, are acknowledged for their substantive inputs to the research design process. Dr. Edward Arens, Chief of the Architectural Research Program, NBS, and Dr. Belinda Collins and Mr. Sanford Adler, both of the Occupant Safety Program, NBS, are all gratefully acknowledged for their editorial assistance. 
As a group, empirical investigators of the responses of building occupants to emergencies employ idiosyncratic, non-replicable techniques for research design, data acquisition, and data analysis. As a result, it has been difficult to explain the influence of many, often uncontrolled, variables. This shortcoming has frequently rendered research findings indeterminate and non-cumulative. This paper explores three exemplary research design strategies, each aimed at mitigating these problems by introducing a greater degree of rigor into the study of human behavior in fires. Both exploratory and experimental designs are considered in various problem contexts. 


\subsection{OVERVIEW}

Our ability to reduce the incidence of deaths and injuries due to building fires depends greatly upon our understanding of human response during fire situations. This notion is widely accepted, and research interest in human behavior in fires has increased during the 1970's. Several reviews document this development (e.g., Rubin and Cohen, 1974, Pauls, 1975; Breaux et.al., 1976; Stahl and Archea, 1977). Reviews of the literature on occupant response to fires have identified three categories of research effort: the development of explanatory models (e.g., Archea, 1977; Bickman, 1977; Stah1, 1976, 1977); the development of specific techniques for gathering data (e.g., Pauls, 1975, 1977); and the description of actual fire events (e.g., Wood, 1972; Bickman, 1976; Haber, 1977; Bryan, 1977; Lerup, 1977).

Three principal categories of explanatory models of occupant behavior in fires have appeared, including: hypothetical models (Archea, 1977); models derived from cognate psychological theory (Stahl, 1976, 1977); and models derived from the analysis of specific case data (Breaux, 1977). These efforts remain largely speculative, however, and no model of occupant behavior in fires is universally accepted.

At present, attempts to develop techniques for data-gathering have focused either on the design of questionnaires, surveys and interview schedules for use after real fires, or upon the development of direct observational techniques which are more-or-less unobtrusive, and are presumed to be accurate and reliable. Survey questionnaires designed by Wood (1972) and Bryan (1977), interview formats developed by Canter et. al. (1976), and videotape recording techniques applied by Pauls (1975) during fire drills are chief examples. To date, however, these techniques, strategies, and instruments have been neither adequately nor independently validated or replicated.

Several investigators have attempted to analyze data from specific fire cases (Wood, 1972; Bryan, 1977; Haber, 1977). These efforts have been primarily descriptive, but, because these studies identify sallent variables for future examination, they may also be classified as heuristic.

Three observations can be made concerning the state-of-the-art of research into occupant response during building fires: First, various investigations provide piecemeal attempts to satisfy descriptive, methodological, or heuristic objectives. Second, rarely have individual researchers even attempted to replicate or cross-validate published results. Finally, the better-known and generally accepted techniques for experimental design and data analysis seem not to have been applied to studies of occupant response to fires. 


\subsection{PROBLEM}

The remainder of our discussion proposes to rectify this last problem. In particular, we shall be concerned with reducing the indeterminacy of research findings which necessarily results whenever data are obtained from poorly controlled situations. Why have these investigators made so little use of rigorous methods of research design and data analysis? The reasons include the likelihood that well-controlled laboratory experimentation cannot replicate all the important aspects of real-life fire conditions, and that as a result, the applicability of inferences drawn from laboratory data may be sharply limited. Other reasons involve the belief that too little is currently known about occupants' experiences in building fires, and that, consequently, any rigorous analysis of specific variables or relationships would be premature. Finally, no investigator wants to subject human occupants to any real or perceived life threat, for research purposes.

\subsection{OBJECTIVES AND APPROACH}

Clearly, the shortcomings enumerated above represent real and important concerns. This paper will provide examples of research designs that could introduce much-needed rigor into the analysis of human response to fires. Designs are considered that, in general, describe and demonstrate the applicability of such approaches as:

(1) systematic exploratory research (Selltiz, et.al., 1959), in which hypotheses and procedures for testing them may arise, ad hoc, as more becomes known about the phenomenon under study; and

(2) field-experimental research (Cook and Campbe11, 1976), in which data from naturalistic settings must be viewed in terms of sources of variance which may be difficult to either identify or control, and in which the behaviors of people are viewed in terms of the experimental manipulation of such settings.

Three designs have been selected for discussion. These examples were chosen in order to provide a variety of both researchable problems, and research strategies. The first problem concerns the question of how "everyday" environmental behavior is transformed into highly stressful "emergency" response. This problem will be considered through systematic exploratory methods. In the second problem, the study of emergency cognition across individual persons and situations is addressed by means of a field-experimental design. Finally, a fieldexperimental design is presented for the purpose of investigating the impact of training programs upon evacuation behavior, and upon safety attitudes. 
2. DESIGN ONE: AN EXPLORATCRY PROCEDURE FOR STUDYING THE TRANSFORMATION OF "EVERYDAY" ENVIRONMENTAL SETTINGS INTO "EMERGENCY" SITUATIONS

\subsection{ISSUES}

Consider, as an example, the problem of occupant responses to fire in an office building. The research objectives are to identify the variables and components of a complex environment-behavior system, and to describe relationships among such components. The "system" at issue concerns changes in physical settings and activity patterns, believed to emerge with the onset of the fire event.

The researcher is likely to find relatively little literature which treats the subject of building emergencies specifically. However, several existing literatures are available which may provide an initial focus, such as the sociological literature on natural disasters, and the psychological literature on stressful environments. These are certainly capable of providing useful points for departure, making it possible to formulate tentative hypotheses for informal evaluation in the field. Examples include hypotheses about the mobilization of groups during various phases of the emergency period, and under a variety of conditions. The work of sociologists Dynes and Quarantelli (1968) for example, on the emergence of task groups during a small-town disaster, offers a basis for such hypotheses.

Initial hypotheses will be crude at best. They can only be expected to relate indirectly to the problem at issue, since they will have been derived from dissimilar contexts (i.e., it is not clear that the social, physical and communicatory structures existing within an office building make it treatable as a "community," in the same sense as we might treat a town or small city).

The specific objectives of the first design are to: (1) formulate the problem for more precise, situation-specific investigation; (2) increase researchers', designers and policy-makers' familiarity with occupants' responses during fires; and (3) elucidate concepts and theoretical notions deriving either from various literatures, or from popular preconceptions. Selltiz et.al. (1959), have referred to these as the goals of exploratory research. As a means for identifying the fundamental variables of a system, and for observing the basic operation of ongoing processes in natural settings, the exploratory approach serves as a precursor to the formulation of predictive models, and to more formal research designs. To achieve these goals in the context of the current problem, the design recommended here is composed of two segments: the experience survey, and the comparative case analysis. 


\subsubsection{Experience Survey}

Selltiz, et.a1., have suggested that the experience survey offers the researcher an opportunity to gather preliminary information vital to the design of case studies. Such surveys may serve to identify hypotheses and crude yes-or-no propositions relevant to the context specifically under study, and they may elucidate for the researcher any factors potentially under his control. Moreover, the experience survey is expected to assist in the identification of study sites, the selection of participant observers, and in the elucidation of difficulties concerning the cooperation of various groups.

Such issues, as we11 as questions derived from the literature or other a priori knowledge acquired by the investigator, shall be incorporated into structured interview schedules. The interviews should present the same questions to diverse respondents (to maximize the opportunity for obtaining multiple viewpoints to the same issues), and should encourage respondents to contribute "new" insights on the problem. Accordingly, a structured listing of "open-ended" questions should be developed and administered.

In selecting respondents for the survey, it is necessary to sample from populations representing relevant diverse viewpoints, and having had appropriate experiences. For the present office building problem, the survey should sample from among groups of secretaries, other office workers, executives, and building visitors, as well as from among populations of management, maintenance, and fire-fighting personnel. In the case of building occupants and users, the survey should include both persons who have and who have not experienced a building fire (in order to compare "how I behaved" with "how I think I would behave if. . " viewpoints). Similarly, management and maintenance respondents should represent both those who have and those who have never been required to deal with a building fire. The fire-fighter sample should primarily include individuals who have had extensive experience with office building emergencies (having, presumably, had many opportunities to actually observe occupant behavior during such crises).

\subsubsection{Comparative Case Analysis}

After the experience survey has been completed and the content of the interviews analyzed, specific study sites may be selected and a detailed research strategy outlined. Although no such preliminary work has actually been conducted in connection with the current problem, the procedure suggested here may be taken as representative of the type of investigatory processes anticipated.

Through this procedure, we wish to explain the dynamic process, wherein a regularly occurring behavioral setting undergoes some form of change 
temporarily, and then (presinzbly) recovers. In order to trace the evolution of such a process, tile case analysis method based on an expanded version of the multiple time series quasi-experimental design (see Campbel1 and Stanley, 1963) is suggested. Time series observations are made on parallel systems which differ in terms of environmental manipulation or inherent system characteristics (refer to Figure 2.1). This approach permits comparisons among groups which differ in their level of emergency preparation. Such comparisons are expected to provide additional dimensions along which to describe humin response to emerging fire condtions, and to yield more complex and realistic hypotheses for future investigation.

Site selection. As discussed above, the experience survey is expected to contribute to the process of study-site selection. Inputs to this process will include information about the availability of suitable buildings, and the responsiveness of owners and other groups to the objectives and practical demands of the study. To reduce overall variance in the measure of emerging response, moreover, study-sites should be selected on the basis of their being matched on such criteria as: (a) Architectural design concept (e.g., office tower with central elevator core), (b) Interior design concept (e.g. " "landscaped" or other open $\rightarrow$ ffice planning), (c) Typical floor area dimensions, (d) Mean population, and (e) Emergency warning and evacuation facilities. An appropriate number of sites so matched shall be selected for study.

Environmental manipulations. The reader has noted in FIGURE 2.1 that two forms of environmental manipulation are utilized to permit a comparative analysis of emergency response under differing conditions. These are: (1) the conduct of emergency training programs, and (2) the sudden interruption of on-going work tasks by unannounced evacuation drills. Consider five study sites. Occupants of study site 非, for example, might experience a building-specific training program which includes walk-through drills, lectures and demonstrations focusing on the problems of life-safety in their own building. In site 非, occupants would also receive building-speciflc pre-emergency training. In addition, trained "floor-captains" would be designated for studyfloors at this site. The training program at building 非 3 would be general in content, with occupants seeing films and hearing brief lectures describing various (non-site-specific) issues in fire safety. Sites $\$ 4$ and $\$ 5$ would receive no training programs.

On the appropriate occasions, sites $\|_{1}$ through $\# 4$ experience evacuation drills. Site $\$ 5$ is a "control" case, since during the study period, settings within this building are subjected to neither of the manipulations discussed. The site designations "非" through "非 5 " - and the manipulations corresponding to each - should be randomly assigned to the selected buildings.

Observations and measures. Data from independent sources may be collected, in an effort to reduce the uncertainty of interpretation (Webb, et.al., 1966). Three possible sources are occupant attitude 
surveys, unobtrusive observations of occupant behavior, and reports by building management personnel.

Interview schedules designed to measure occupants' 1 i fe-safety attitudes may be administered to a different sample of occupants at each site, in accordance with the research design (excluding the period associated with evacuation drills). Respondents would include secretaries, executives, and visitors, and should be randomly selected from populations occupying designated study-floors within the sites. Attitudes may be tapped along three dimensions, including persons' expectations of their own performance, expectations and beliefs about their buildings' " 1 ife safety potential," and attitudes about working in high-rise office buildings in general.

Unobtrusive observations of evacuation behavior could be conducted by participant observers, stationed for this purpose. Randomly selected individuals (secretaries and executives - not the same individuals as those interviewed above) could be observed and tracked by an observer assigned to each, with this procedure occurring at each site. The same subjects will be observed during each occasion prescribed by the research design. Participant observers could be co-workers of the persons observed, and would be selected on the basis of physical, social and task distance factors separating the two individuals, and other opportunities for protecting the secrecy of the observers' purpose.

During observation periods, observers would rank subjects' movement patterns, and note stimuli which seem to initiate changes in behavior, apparent objectives of behavior, forms of activity involved, and qualities of behavior (e.g., intensity, unusualness, appropriateness, effectivity; from Selltiz et.a1.). Observers will record data relating to these variables on prepared rating forms, to the extent that doing so does not jeopardize their "cover." Such forms will be supplemented by intensive debriefing sessions immediately following each observation period. Observation periods may consist of one-hour sessions, randomly sampled from workdays. In the case of the evacuation drill observation, subjects will be tracked for a period of one hour, beginning with the onset of the alarm signal. The foregoing discussion describes an ideal research approach, and the ethical difficulties associated with uninformed participation by subjects are recognized, and need to be addressed.

Finally, the perceptions of building management and maintenance personnel could be recorded through interview techniques. Schedules must be designed to assess their opinions about circulation and movement patterns through the building. The objective of pre-drill interviews is the identification of perceptions about potential points of congestion, crowding and blockage. Post-drill interviews should focus on the observance of particular trouble spots during evacuation drills, and the building's general return to normalcy. 


\subsubsection{Summary of Procedure}

The following outline briefly describes the sequences of recommended research activities:

(1) Conduct experience survey; select study sites and participant observers; identify any initial hypotheses that may be worth testing in the field.

(2) Conduct "baseline" (pre-fire training) observations and attitude assessments. Data gathering techniques should be continually updated to reflect the need to field-test new hypotheses discovered during this phase.

(3) Administer training programs to occupants of designated study floors.

(4) Conduct post-training observations and interviews utilizing updated techniques. Update again, to field test any additional hypotheses discovered in the field during this phase.

(5) At a randomly selected point in time, conduct evacuation drills at each of the designated sites. For a period of time (say, one hour) following the onset of the emergency alarm, conduct participant observations only and record data required. Update the observation technique, as required.

(6) Measure post-drill behavioral and attitudinal variables approximately two weeks following the drill, during randomly selected periods at each site.

(7) Debrief all participants.

\subsection{UTILITY OF THE DESIGN}

Fires frequently occur during periods of normal building usage, and consequently they present significant disruptions to occupants' daily routines. In a very real sense, everyday environmental settings are transformed - often suddenly - into potentially 1 ife-threatening situations, during the course of a fire. At present, extremely little is known about the mechanisms underlying such transformations, at the individual building scale. Appropriate hypotheses seem difficult to formulate, experience still must be gained in sampling and experimental design, and even the selection of variables for study is not always straight forward.

Similar difficulties were confronted by researchers investigating human responses to large scale natural disasters (floods, earthquakes). In that domain, various techniques comprising exploratory, or holistic 
methodology have proven useful in the identification of appropriate variables, hypotheses, and methods for more detailed analysis. The design presented above provides a means for applying the exploratory approach at the building scale. The design is recommended with the expectation that a well-laid framework will pave the way for the conduct of more analytical, problem oriented studies. 


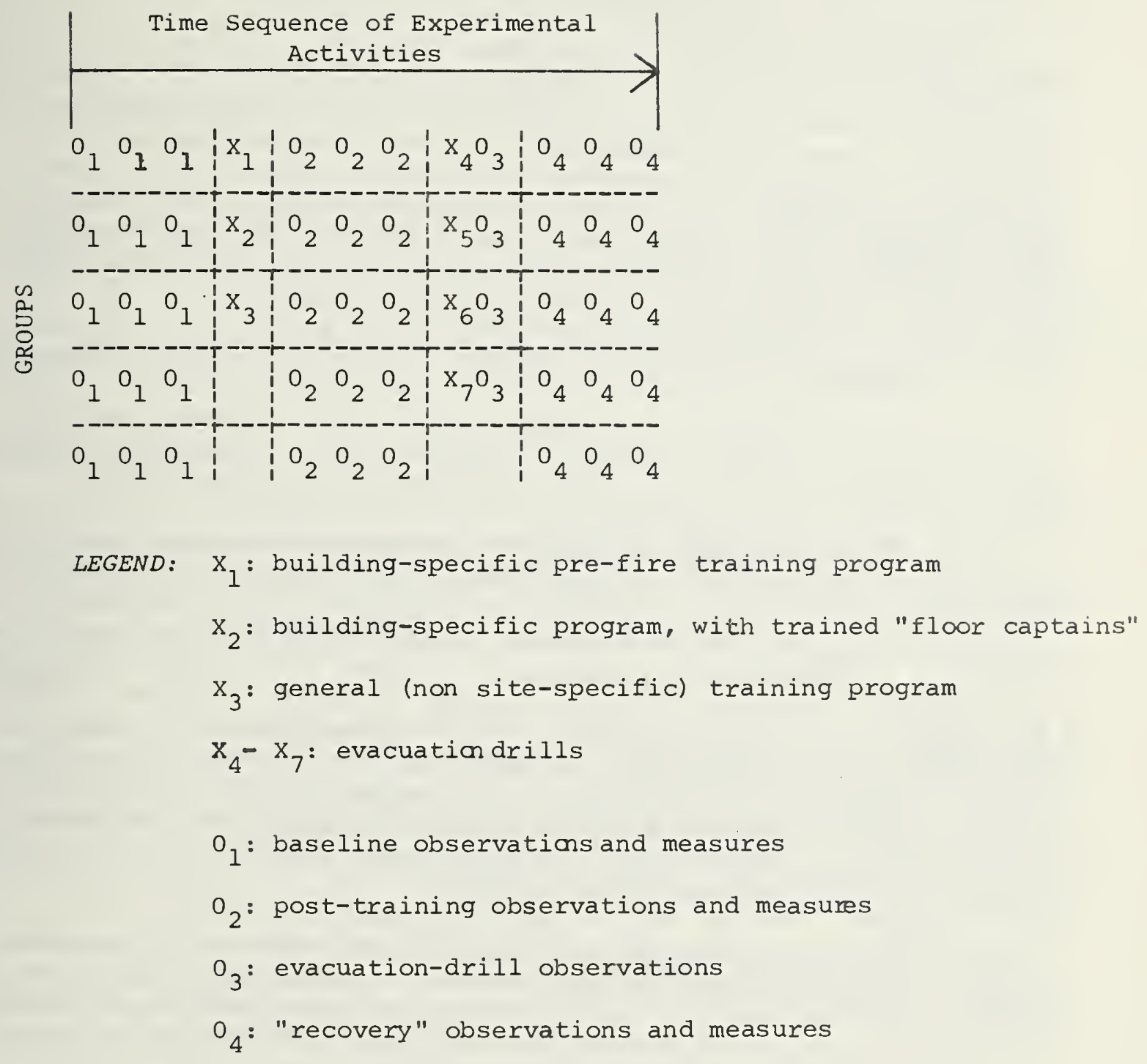

Figure 2.1 Application of Campbell and Stanley's "Multiple Time Series" Research Design 


\subsection{ISSUES}

Theoretical conceptualizations have begun to emerge suggesting the existence of some relationship between "cognitive sets" held by individual occupants, environmental and social context, and actions actually taken during a fire situation (Breaux et.al., 1976; Stahl, 1977; Bickman, 1977). By cognitive set I mean the complex network of attitudes and prior experiences through which humans are predisposed to interpret, organize, and respond to current events.

These conceptualizations have given rise to two interesting hypotheses:

(1) "Within-context" variation: occupants of complex environments (office buildings, schools, hospitals, etc.) cluster into groups which differ on the basis of their emergency predispositions; and

(2) "Across-context" variation: emergency responses vary across environmental and social contexts, even for a single individual.

Consider a research design developed to study these general hypotheses. The class of independent variables of interest in our study of the first hypothesis is that which defines occupant diversity. Salient variables would appear to include occupant' sex, location within the building, and functional role. Independent variables relevant to our study of the second hypothesis, by contrast, include measures of role diversity (e.g., a head-of-household versus a single habitant; an upper echelon or managerial employee versus low-level functionary), and environmental diversity (e.g., at home versus at work).

In both cases, the dependent variables include measures of occupants' predispositions toward fire emergencies. In general, emergency predispositions are seen as complex systems involving emotion and motivation, beliefs and expectations about one's own performance, likelihood of success during a fire situation, and perception of one's role and social responsibility. Moreover, predisposition systems are presumed to operate along an orientation dimension, as well. That is, an individual may have distinct emergency predispositions with regard to self, other persons, and physical objects in the environment.

\subsection{METHODS AND PROCEDURE}

The first hypothesis considered above advances the idea that a given population will cluster into smaller groups on the basis of, for example: occupants' locations within a building, sex, functional role, and other factors which influence emergency cognitive sets and predispositions. The second hypothesis suggests that sets and predispositions are not invariant, even for a single person: as he moves from one social or 
environmental setting to another, his basis for responding to an emergency changes. The problems of identifying clusters within larger populations, and of monitoring changes in cluster content over time, have been dealt with through "Q-Methodology" (Stephenson, 1953;

Kerlinger, 1973). Q-Methodology employs a technique enabling a subject to rank-order stimuli of various kinds, and to reflect his attitudes, beliefs, or dispositions toward such stimuli.

Individuals record their responses by means of a card-sort instrument (called a "Q-sort") on which subjects register the degree to which they approve of particular statements. These statements are written on the cards, and as the subject considers each card, he sorts it into an appropriate pile (e.g., pile $\|_{1}$ for statements least agreed with; pile 非 for statements most agreed with). The specific design of the Q-Sort instrument is discussed below, as are methods for analyzing Q-data.

\subsubsection{Instruments}

The research instrument for the current problem would consist of Q-sorts, structured in such a way that the statements to be rank-ordered are descriptive of the variables related through the hypotheses. According to Stephenson, such a structure is necessary to insure that the instrument tests the hypothesis in question, and not the individual subject, per se.

Statements for inclusion in the Q-Sort are constructed by considering two dimensions. These are (1) the general affective direction of emergency attitudes or predispositions (i.e., reasonable-logical versus emotionalirrational), and (2) the orientation of predispositions (i.e., toward the self, other people, or the physical environment). This organization simulates a factorial design consisting of six cells (see Figure 3.1). In a given Q-sort instrument, each cell might contain a number of statements, every such statement exemplifying the definition of the cell. Finally, every statement is typewritten onto cards, and the resulting deck of cards shall comprise the particular Q-sort instrument. Sample statements are given in Figure 3.2

Stimulus statements utilized in the Q-technique may themselves focus on various aspects of emergency cognitive sets. Some important areas are: expectations of own (and others') performance in an emergency, beliefs about chances for success or survival, attributions of causes and the behavior of others, affects, and motives. A useful approach to these five issues involves the construction of five separate Q-instruments, each including statements of one type. In this way, the analysis would be capable of pinpointing specific contributions to attitude differentials.

The actual material for use as statements in the instruments will result from exploratory investigations involving open-ended interviews and projective tests. Appropriate items would also be culled from extensive surveys of the anecdotal and journalistic literature on fire incidents, 
and from archival materials and official fire reports. Subjects for interview and projective procedures should be drawn from the same populations as will subjects who finally perform the Q-sorts. During the instrument construction phase fire victims and fire fighters might also be interviewed.

\subsubsection{Subjects and Field Sites}

Hypothesis (1). "Within-context" variation may be studied in a sample of office buildings, which should be selected on the basis of their matching on such criteria as: location with the city, architectural design and spatial configuration, height and size, tenant variety, number and position of egress alternatives, availability of fire suppression systems (or lack thereof), and emergency history.

Subjects for the Q-sort procedure are selected from the study sites to reflect a three-dimensional factorial design (see Figure 3.3). As discussed earlier, the dimensions include: functional role within the building (upper-echelon management, low-level functionary, visitor), location within the building (top $k$ stories, bottom $k$ stories), and sex. Subjects in each cell should be matched for such factors as age, history of fire involvement, familiarity with the building's layout, and participation in evacuation drills or other emergency training programs.

Hypothesis (2). The examination of "across-context" variation employs another set of subjects drawn from the sample of study sites described above. Subjects are again matched on the basis of criteria outlined above. Here, however, subjects are selected to reflect a two-dimensional design. These dimensions are: functional role within various environmental contexts (i.e., head-of-household versus single-habitant, upperlevel managerial employee versus low-echelon worker), and sex (refer to Figure 3.4).

In order to test predispositional variations across roles and contexts, each subject performs the Q-sort task for each of two situations: potential fires in both the home and work environments. In effect, then, the design is expanded into a three-dimensional arrangement.

\subsubsection{Procedure}

Data Gathering. Subjects in each design sort Q-decks by distributing cards into piles reflecting the degree to which they agree or disagree with the statement contained, (as discussed above). Persons are instructed to sort only the designated number of cards into each pile, so that the Q-sort will reflect a quasi-normal distribution across the agreement continuum (Stephenson, 1953). For each subject, the score for any statement will be taken as the numerical value of the pile in which it was placed. 
Data Analysis. Statement scoies can be correlated for each pair of respondents, and the resulting correlation matrix can be factor analyzed. The resulting factors, or clusters, will contain persons who distributed the Q-sorts similarly. This procedure may be repeated for each Qinstruments as are actually administered. Support for the hypotheses can be inferred if person-clusters reflect those postulated (refer to Figures 3.2 and 3.3 ).

An additional test of either hypothesis may be achieved through the analysis of variance. Here, the means of statement scores for all Ss in a cell may be compared to assess the direction of emotionality and locus of orientation of persons within that cell. Qualitative support for either hypothesis might then be assumed if inter-cell differences in emotionality and orientation are in appropriate directions. The hazards of conducting analysis of variance in a non-experimental context should be recognized. The use of more stringent significance levels (say the .01 level), however, may permit us some confidence in using ANOVA as a secondary or supportive test in this case (as suggested by Kerlinger, 1973).

\subsection{UTILITY OF THE DESIGN}

The analytical investigation of human responses to fire poses many complex problems. Chief among these are the identification of important qualities of occupants' emergency response, the establishment of research settings which facilitate the study of these qualities, and the gathering of valid data. Traditional laboratory experimentation may provide the most convenient and economical means for investigating certain well-defined problems (e.g., the visual perception of 11 luminated exit signs through smoke of varying density). However, the contrived laboratory setting may be unable to provide the richness and variation of experience found in our everyday use of buildings. Consequently, the "field experiment" seems appropriate. Here, experimental or quasiexperimental manipulations are conducted directly upon actual settings, as these settings occur within the environment. Subjects are "real people," engaged in their normal, everyday tasks (save, of course, for periodic interventions by the experimenter).

In the design reviewed above, the field-experimental approach was recommended for studying perception and cognition with respect to potential fire emergencies. The execution of this design is expected to yield data suggesting ways in which persons who differ in their predispositions toward fires may in fact behave during real emergencies. 


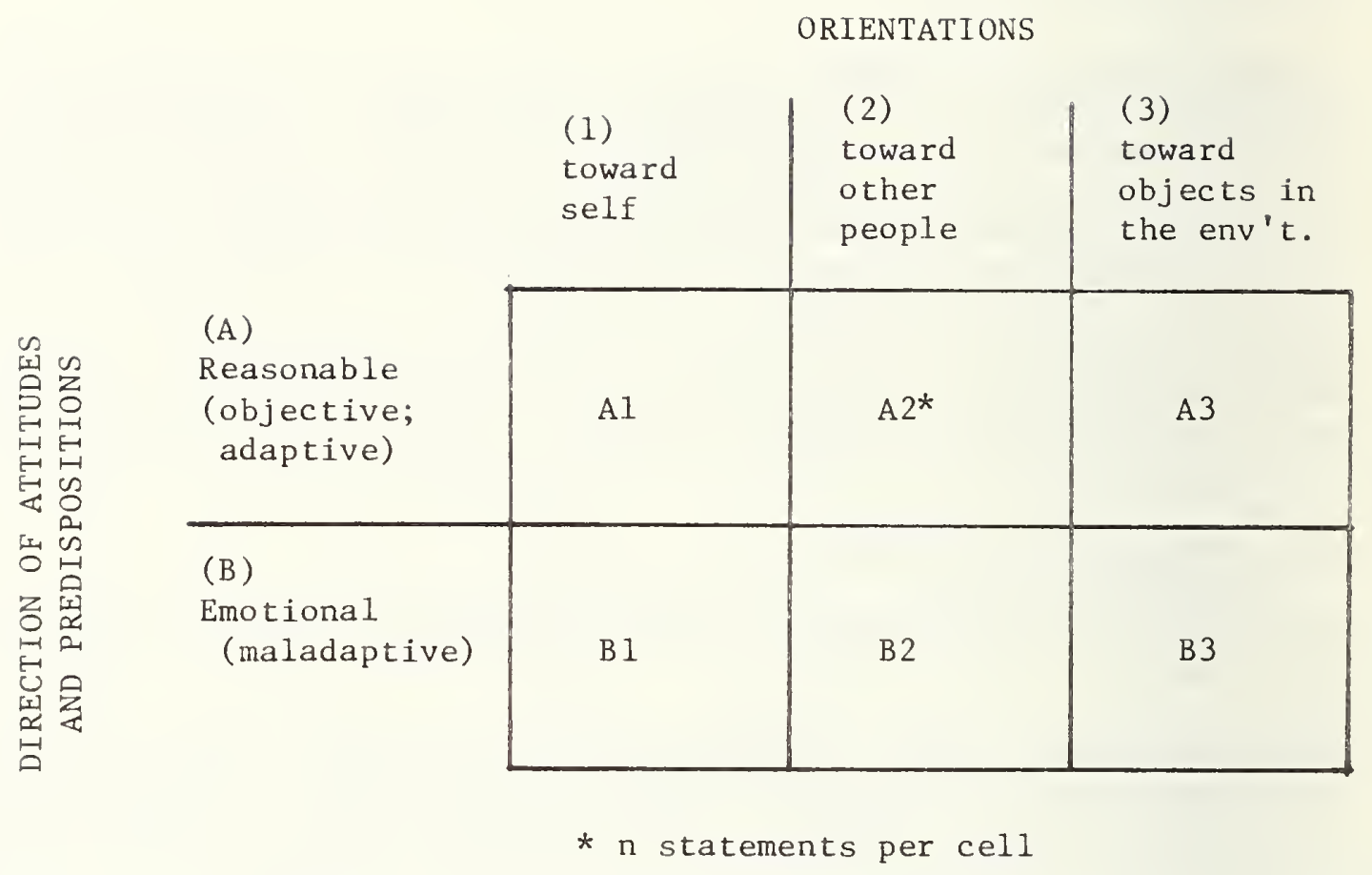

Figure 3.1 Factorial Structure of Q-Sort Statement Categories 
"If I ever heard the fire alarm go off in this building, I'd walk toward the nearest stairway, and proceed to the street."

CELL B1: Emotional / Toward self

"I think I'd panic if I ever heard the fire alarm go off."

CELL A2: Reasonable / Toward other people

"If there was ever a fire here, I'd try my best to warn other occupants before evacuating myself."

CELL B2: Emotional / Toward other poeple

"Personally, I don't think you could trust anyone when disaster strikes."

CELL A3: Reasonable / Toward objects in the environment "In the event of a fire, I'd make a reasonable attempt to secure irreplaceable documents. But, I'm only human."

CELL B3: Emotional / Toward objects in the environment

"I could never evacuate my room without collecting my family-photos." 


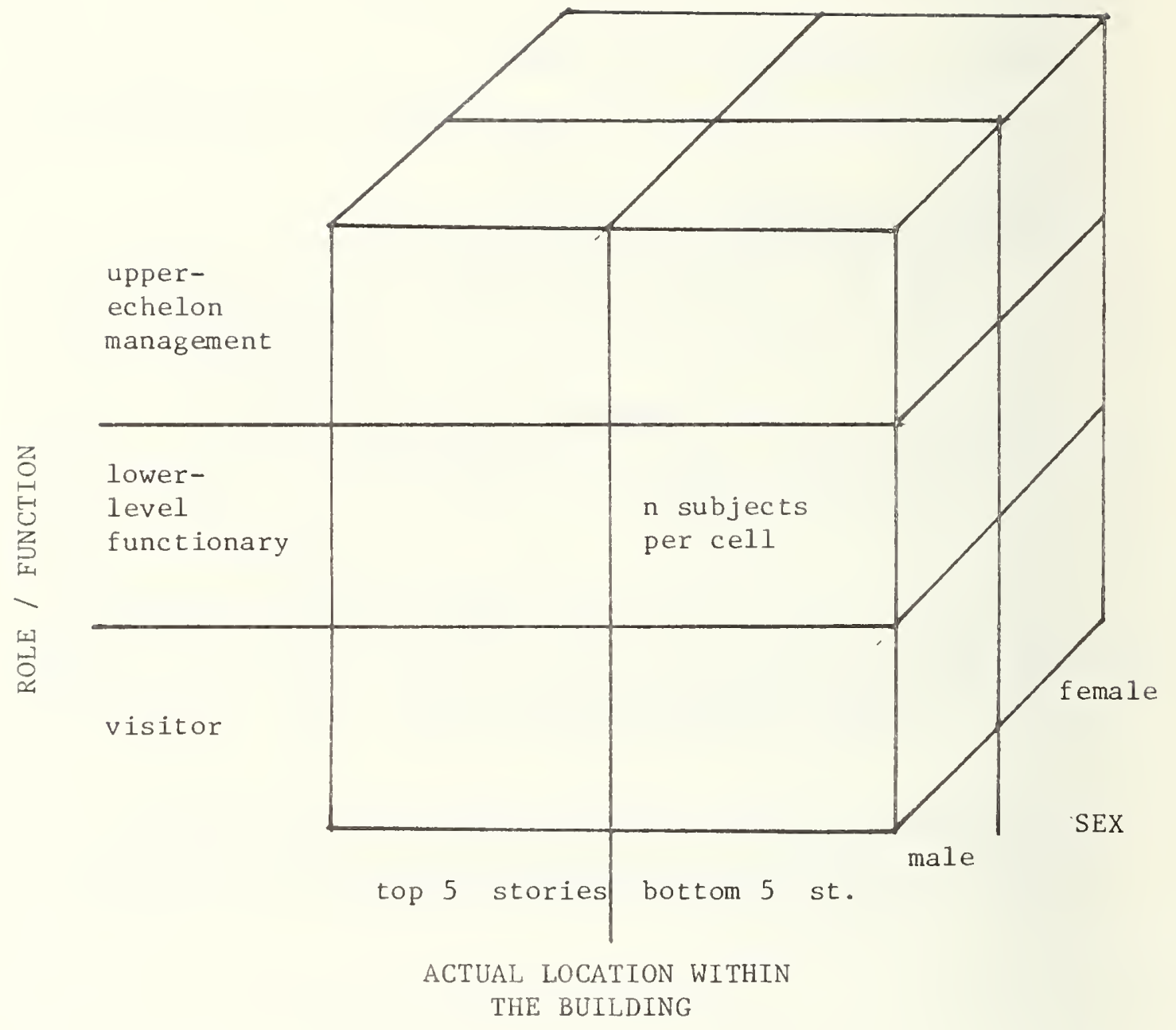

Figure 3.3 Factorial Design for Hypothesis (1) 


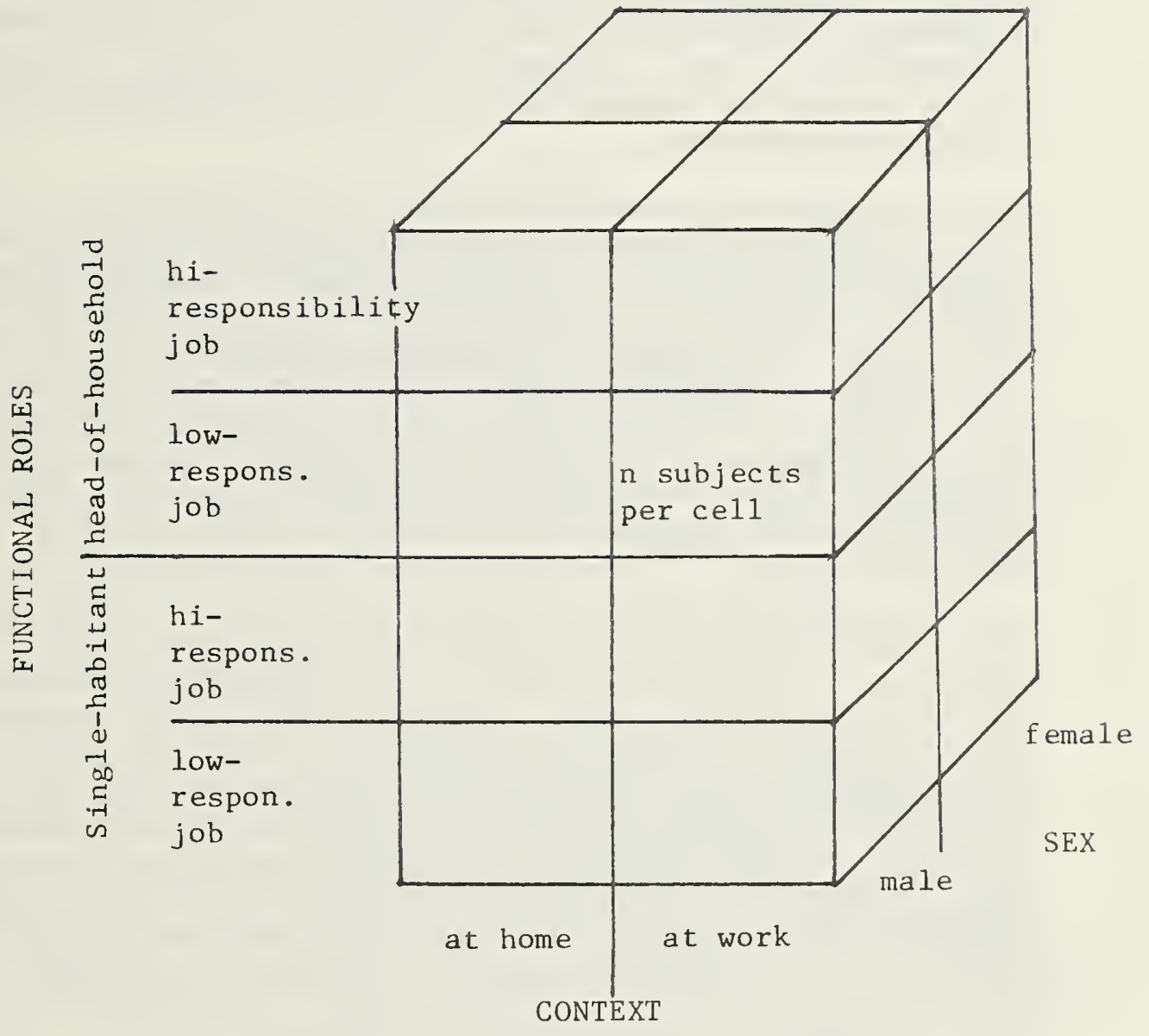

Figure 3.4 Factorial Design for Hypothesis (2) 
4. DESIGN THREE: A FIELD-EXPERIMENTAL DESIGN FOR EVALUATING EMERGENCY TRAINING PROGRAMS

\subsection{ISSUES}

The question of whether pre-emergency training programs are effective in promoting appropriate behaviors during actual fire emergencies has been asked many times. However, empirical treatment of this problem is generally unavailable. Even Pauls (1975), who recorded pedestrian flow patterns in exit stairways during fire drills in high-rise office buildings, did not systematically investigate the influence of training or drill performance.

Let us consider an expansion of Paul's investigation, and consider relationships between the physical design of buildings, occupants' emergency cognitive sets, and the influence of such relationships upon training and drill effectiveness. Specifically: (a) what are the effects of pre-emergency training on the probability that occupants will recognize effective egress routes and safety-related elements in the environment, in the event of a building fire? (b) are the effects of training programs influenced by variations in the complexity of a building's physical layout and design? Again, we use an office building as an example.

On the assumption that the quantity and quality of physical-environmental stimuli may interact with training programs intended to promote adaptive responses to stressful situations, two hypotheses are offered as tentative answers to the above questions: (a) in both complexly and simply organized office buildings, significantly more occupants receiving building-specific pre-emergency training will recognize effective egress routes and a larger number of safety-related design features, than will occupants receiving no training; and (b) occupants participating in a general (non-building-specific) training program will recognize effective egress routes, and safety-related design features, significantly more frequently in buildings of simple - rather than complex - organization.

\subsubsection{Concepts and Operational Definitions}

The two independent variables include "building organization," and "type of pre-emergency training program". Building organization is defined here in terms of two levels: simple and complex. Simple physical organizations may be characterized by "open" floor plans which permit visual access to means of egress from most points on the floor, and by short, linear circulation routes. Complex organizations, in contrast, are denoted by the subdivision of floor areas into many small spaces (each with an extremely 1 imited view of egress routes) and by lengthy, meandering corridor networks. The emergency training variable is defined in terms of three levels, including participation in "building specific" or "general" pre-emergency training programs, or participation in no program at a11. These programs have already been described earlier. 
The two dependent variables to be measured include "recognition of adaptive emergency egress routes", and "recognition of safety-related features and objects in the environment". Recognition of egress routes is measured by scoring the quality of routes on maps created by occupants during an exercise. The number of safety-related features (e.g., communications apparatus, operable windows, fire doors, etc.) included in a subject's map is taken as his score on this variable. The mapping task requires subjects to recall routes and features without any prior warning, approximately two weeks following the completion of training programs. Maps should be rated independently by a number of judges.

\subsection{METHODS AND PROCEDURE}

4.2.1 Design

A $2 \times 3$ factorial design is indicated by the above discussion, and we shall consider subjects randomly assigned to each cell (refer to Figure 4.1a). The basic approach is primarily an expansion of the posttest only control-group design (Campbell and Stanley, 1963), and is described in Figure 4.1b. An additional expansion of the design may be adopted, however, which permits "retrospective-pretest" (Campbell and Stanley, p. 66) measures (denoted by "(0)" in Figure 4.1c) to be utilized in distinguishing between subjects who vary on such factors as previous experience in building fires or with safety programs, predispositions to anxiety in connection with potentially stressful or dangerous situations, etc.

\subsubsection{Selecting Research Sites}

Buildings are selected from a population of office structures matched along the following criteria: (a) architectural design concept,

(b) typical floor area dimensions, (c) mean population, and (d) emergency warning and evacuation facilities. A population so defined is subdivided into two categories: those having relatively simple, and those having complex spatial organizations on typical study-floors. Buildings in each sub-category should then be pretested to cross-validate the simplicity-complexity perceptions of the research judges with those of actual users. Sites of each type are selected, representing to the extent possible, extremes of simplicity and complexity, as defined by users' own ratings. Subjects interviewed in the site-selection pretest should work neither for the same tenant, nor on the same floor, as participants in the main experiment.

Finally, study-floors are selected at the sites, from among those floors in the building judged representative of the structure's simplicity or complexity characteristic. 
From the study-floor of each site, female secretaries may be randomly selected. Subjects range from between 25 and 30 years of age, and may not otherwise be matched.

\subsubsection{Outline of Procedure}

In summary, such a study may be implemented through the following procedure.

(1) Select study-sites (and study-floors).

(2) Randomly select subjects at each site.

(3) Randomly assign sites to the treatment categories (training program types: specific, general or none), such that there are two sites per category.

(4) Administer the training programs.

(5) Administer the mapping task at a randomly selected time, approximately two weeks after completion of the training program. Subjects are individually called into an office temporarily occupied by the reseacher for this purpose, and are asked to (a) "map their way out of the building" (from their own work stations) in the event of a fire alarm, and to (b) identify and locate various features and objects in the environment which might be useful during the emergency period.

(6) Approximately two weeks after the mapping task, interview all subjects for the purpose of collecting retrospective-pretest data, such as previous experience with actual fires and/or safety training, predispositions to anxiety, etc.

(7) Debrief all participants.

\subsubsection{Data Analysis: A Brief Note}

Analysis of covariance (ANCOVA) may be utilized to assess experimental effects taking into account any variation among Ss along the covariate measures. Snedecor and Cochran (1967) have demonstrated the expansion of ANCOVA to the case of multiple covariance in a two-way design.

However, this technique would require separate and independent analyses for each dependent variable (route and feature recognition). To account for the possibility of interdependency between these variables, either a multi-variate extension of two-way multiple covariance analysis, or a canonical regression analysis would be indicated. 


\subsection{UTILITY OF THE DESIGN}

The ultimate effectiveness of emergency training programs is an important issue, and the evaluation of such programs may raise complex problems. For example, several factors may operate in unison during a single drill or practice event, and the relative contribution of each may be difficult to ascertain. Moreover, the mock-fire may not adequately replicate important qualities of a real emergency, rendering the question of just what is being evaluated virtually indeterminate, and worse, leaving the participants ill-prepared.

Again, a field experimental research scheme has been suggested. Through the application of the approach described above, a systematic investigation of the relative contribution of multiple factors is possible. In addition, the naturalistic field setting permits, to as great a degree as possible, subjects to respond to the environments and situations with which they are already familiar, and which have some meaning in the context of their everyday lives. 
PHYSICAL LAYOUT AND DESIGN

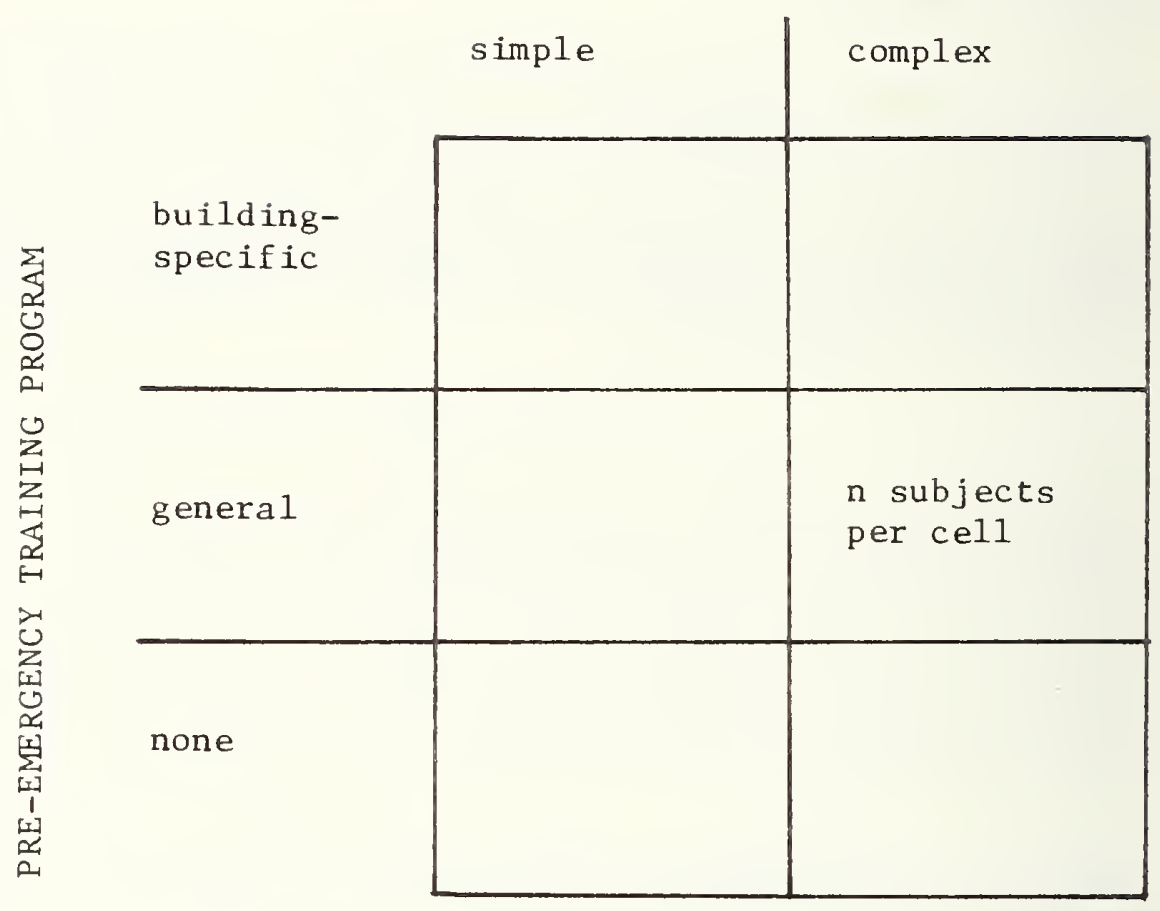

Figure 4.1 (a) $2 \times 3$ Factorial Design 


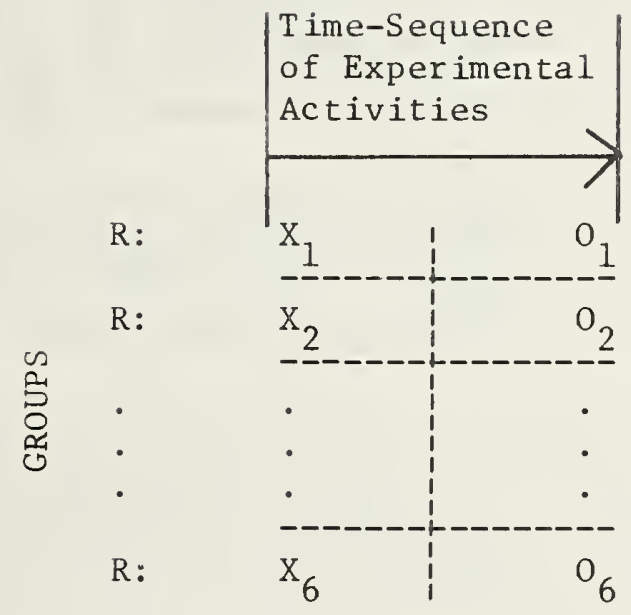

LEGEND: R: subjects are randomly assigned to each group

$x_{1}-x_{6}:$ experimental manipulations

$\mathrm{O}_{1}-\mathrm{O}_{6}$ : observations and measures

Figure 4.1(b) Expansion of Campbell and Stanley's "Post-Test Only Control-Group" Design 


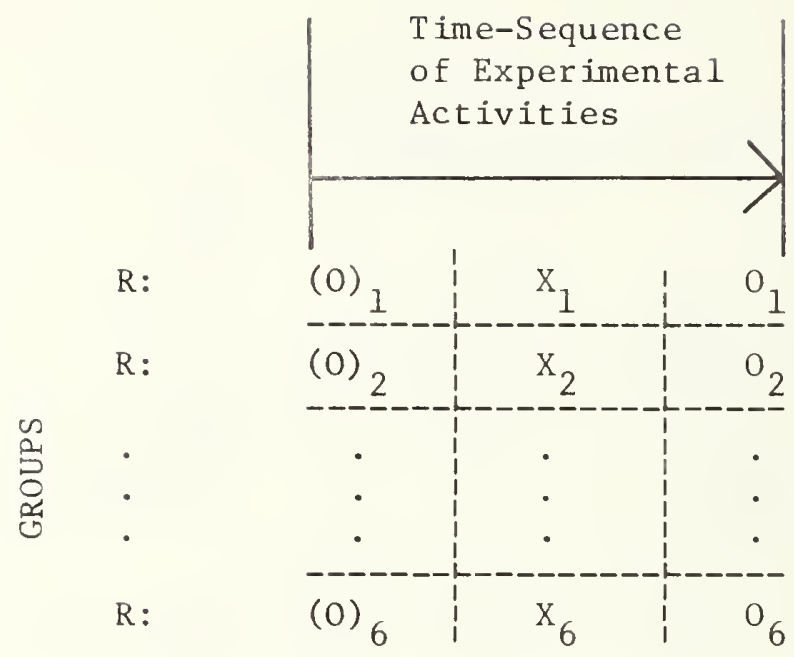

LEGEND: R: Subjects are randomly assigned to each group

(0) $1-(0)_{6}:$ Retrospective pretest measures

$\mathrm{X}_{1}-\mathrm{X}_{6}$ : experimental manipulations

$\mathrm{O}_{1}-\mathrm{O}_{6}:$ observations and measures

Figure 4.1(c) Design expanded to include "Retrospective Pretest" Covariate Measures 


\section{SUMMARY}

Our ability to reduce the incidence of deaths and injuries due to building fires depends greatly upon our understanding of human responses during fire situations. Unfortunately, however, no universally accepted model of occupants' responses during fires is currently available. Moreover, doubt surrounds the validity and reliability of data-gathering techniques now applied to this problem. The consequence is that knowledge development is neither cooperative, complementary, nor cumulative.

This report presented three research designs, each aimed at mitigating this problem by introducing additional levels of analysis into the study of responses to fires. Both exploratory and experimental procedures were were considered in various problem contexts.

The problems of building egress and of occupants' response to fire are special foci of several programs in the United States, including those of the Center for Building Technology and the Center for Fire Research, both of the National Engineering Laboratory, National Bureau of Standards. Research designs of the type suggested here are particularly suited to the goals of these programs. Consequently, a major effort employing more rigorous methods of analyzing human responses in building emergencies is anticipated. But this effort will succeed only to the extent that valid and well-founded data bases inform life safety design regulation. Behavioral science contributions must be shown to be at least as informative as the traditions of engineering practice. 
Archea, J. Personal communications. Washington, D.C.: U.S. Dept. of Commerce, National Bureau of Standards, 1977.

Bickman, L. A nursing home fire. Presented at the Seminar on Behavior in Fires, Surrey, U.K., Univ. of Surrey, 1976.

Bickman, L. A model of human behavior in a fire emergency. Chicago: Loyola Univ. of Chicago, Applied Social Psychology, 1977.

Breaux, J., Canter, D. and Sime, J. Psychological aspects of behavior of people in fire situations. Surrey, U.K.: Univ. of Surrey, Fire Research Unit, 1976.

Breaux, J. Personal communications. Surrey, U.K.: Univ. of Surrey, Fire Research Unit, 1977.

Bryan, J. L. Smoke as a determinant of human behavior in fire situations. Washington, D.C.: U.S. Dept. of Commerce, National Bureau of Standards, NBS-GCR-77-94.

Campbell, D. and Stanley, J. Experimental and quasi-experimental designs for research. Chicago: Rand McNally, 1963.

Canter, D., Breaux, J. and Sime, J. Personal communications. Surrey, U.K.: Univ. of Surrey, Fire Research Unit, 1976.

Cook, T. and Campbe11, D. The design and conduct of quasi-experiments and true experiments in field settings. In Dunnette, M. (ed.), Handbook of industrial and organizational psychology. Chicago: $\overline{\text { Rand McNa }} \overline{11 y, 1976 . ~}$

Dynes, R. and Quarantelli, E. Group behavior under stress. Sociology and social research, 1968, 52, 4, 416-429.

Haber, G. Fire as environment. Washington, D.C.: U.S. Dept. of Commerce, National Bureau of Standards, Unpubl. ms., 1977.

Kerlinger, F. Foundations of behavioral research. New York: Holt, Rinehart and Winston, 1973.

Lerup, L. People in Fires: a manual for mapping. Berkeley, Ca.: Univ. of California, College of Environmental Design, Architecture Life Safety Group, 1977.

Pauls, J. Movement of people in buildings. Presented at the Symposium on Human Response to Tal1 Buildings, Chicago, July 1975. 
Pauls, J. Management and movement of building occupants in emergencies. Presented at the Conference on Designing to Survive Severe Hazards, ITT Research Institute, Chicago, November 1977.

Rubin, A. and Cohen, A. Human behavior in building fires. Washington, D.C.: U.S. Dept. of Commerce, National Bureau of Standards, $\mathrm{TN}-818,1974$.

Selltiz, C., Jahoda, M., Deutch, M. and Cook, S. Research methods in social relations. New York: Holt, Rinehart and Winston, 1959.

Snedecor, G. and Cochran, W. Statistical Methods, 6th Edition. Ames, Iowa: Iowa State Univ. Press, 1967.

Stahl, F. Some prospects for simulating human behavior in high-rise building fires: a pilot demonstration. In Suedfeld, P. and Russell, J. (eds.), The behavioral basis of design, Book 1. St rouds burg, Pa.: Dowden, Hutchinson, and Ross, 1976.

Stahl, F. Simulating human behavior in high-rise building fires. Washington, D.C.: U.S. Dept. of Commerce, National Bureau of Standards, NBS-GCR-77-92, 1975, issued 1977.

Stah1, F. and Archea, J. An assessment of the technical literature on emergency egress from buildings. Washington, D.C.: U.S. Dept. of Commerce, National Bureau of Standards, NBSIR 77-1313, 1977.

Stephenson, W. The study of behavior: Q-technique and its methodology. Chicago: Univ. of Chicago Press, 1953.

Webb, E., Campbe11, D., Schwartz, R. and Sechrest, L. Unobtrusive measures. Chicago: Rand McNally, 1966.

Wood, P. G. The behavior of people in fires. London: Dept. of the Environment and Fire Officers' Committee, Joint Fire Research Organization, November 1972. 
NBS.114A REV. 11-77

\begin{tabular}{|c|c|c|}
\hline $\begin{array}{l}\text { 1. PUBLICATION OR REPORT NO. } \\
\text { NBSIR 78-1508 }\end{array}$ & $\begin{array}{l}\text { 2. Gov't Accession } \\
\text { No. }\end{array}$ & 3. Recipient's Accession No. \\
\hline \multirow{2}{*}{\multicolumn{2}{|c|}{ Human Response to Fire: Three Designs for Research }} & $\begin{array}{l}\text { 5. Publication Date } \\
\text { August } 1978\end{array}$ \\
\hline & & 6. Performing Organization Code \\
\hline Fred I. Stahl & & 8. Performing Organ. Report No. \\
\hline \multirow{2}{*}{\multicolumn{2}{|c|}{$\begin{array}{l}\text { 9. PERFORMING ORGANIZATION NAME AND ADDRESS } \\
\text { NATIONAL BUREAU OF STANDARDS } \\
\text { DEPARTMENT OF COMMERCE } \\
\text { WASHINGTON, D.C. } 20234\end{array}$}} & $\begin{array}{c}\text { 10. Project/Task/Work Unit No. } \\
7431121\end{array}$ \\
\hline & & 11. Contract/Grant No. \\
\hline \multirow{3}{*}{\multicolumn{2}{|c|}{ 12. Sponsoring Organization Name and Complete Address (Street, City, State, ZIP) }} & $\begin{array}{l}\text { 13. Type of Report \& Period } \\
\text { Covered Interim: }\end{array}$ \\
\hline & & Nov 1977 - Jan 1978 \\
\hline & & 14. Sponsoring Agency Code \\
\hline
\end{tabular}

15. SLPPLEMENTARY NOTES

16. ABSTRACT (A 200word or less tactual summary of most significant information. If document includes a significant bibliography or literature survey, mention it here.)

As a group, empirical investigators of the responses of building occupants to emergencies employ idiosyncratic, non-replicable techniques for research design, data acquisition, and data analysis. As a result, it has been difficult to explain the influence of many, often uncontrolled, variables. This shortcoming has frequently rendered research findings indeterminate and non-cumulative. This paper explores three exemplary research design strategies, each aimed at mitigating these problems by introducing a greater degree of rigor into the study of human responses to fires. Both exploratory and experimental designs are considered in various problem contexts.

17. KEY WORDS (six to twelve entries; alphabetical order; capitalize only the first letter of the first key word unless a proper name; separated by semicolons)

Architectural psychology; environmental psychology; fire escape; fire safety; human research; research design.
18. AVAILABILITY
$\mathrm{X}$ Unlimited

For Official Distribution. Do Nor Release to NTIS

Order From Sup. of Doc., U.S. Government Printing Office Wa shington, D.C. 20402, SD Stock No. SNO03-003

[x Order From National Technical Information Service (NTIS) Springfield, Virginia 22151

\begin{tabular}{|l|c|}
\hline $\begin{array}{l}\text { 19. SECURITY CLASS } \\
\text { (THIS REPURT) }\end{array}$ & 21. NO. OF PAGES \\
UNCL ASSIFIED & 31 \\
\hline $\begin{array}{l}\text { 20. SECURITY CLASS } \\
\text { (THIS PAGE) } \\
\text { UNCLASSIFIED }\end{array}$ & 22. Price \\
\hline
\end{tabular}

